\title{
Analisis Laba Sosial Atas Investasi: Menyibak Asap Panen Madu Hutan Gambut untuk Kesejahteraan yang Lebih Cerah
}

\author{
Rezaldi Alief Pramadha ${ }^{1}$, Vandy Yoga Swara², Rudi Hartono ${ }^{3}$, Danny Satria Wijaya ${ }^{4}$, \\ Rahmad Hidayat ${ }^{5}$
}

\begin{abstract}
Abstrak
Artikel ini menunjukkan bagaimana inisiatif keberlanjutan perusahaan pada program Corporate Social Responsibility (CSR) PT Pertamina RU II Sungai Pakning, yaitu Budidaya Madu Hutan Gambut yang memiliki dampak signifikan terhadap perubahan sosial, ekonomi, dan lingkungan di tingkat masyarakat. Data mengenai pelaksanaan program dan bentuk perubahan yang dirasakan diperoleh melalui laporan implementasi perusahaan dan wawancara via telepon dengan perusahaan serta penerima manfaat yang diolah dengan menggunakan metode Laba Sosial atas Investasi atau Social Return on Investment (SROI). Hasil penelitian menunjukkan bahwa praktik usaha pencarian madu hutan yang minim risiko kebakaran lahan terbukti meningkatkan kesejahteraan penerima manfaat dan pemangku kepentingan lain yang dibuktikan dengan hasil SROI sebesar 1,1. Rutinitas penerima manfaat dalam menjalankan pekerjaan utama menghasilkan madu dan kapasitas penerima manfaat dalam menindaklanjuti program berperan penting dalam proses pembentukan nilai dampak. Hasil ini tidak terlepas dari model intervensi CSR yang mengarah pada produk ramah lingkungan, inovasi teknologi, sertifikasi, dan penciptaan lapangan kerja. Studi ini mengkonfirmasi teori doughnut economics dan modal manusia.
\end{abstract}

Kata kunci: corporate social responsibility, doughnut economics, human capital, pemberdayaan masyarakat, laba sosial atas investasi

\begin{abstract}
This article shows how corporate-based sustainability initiatives in Corporate Social Responsibility (CSR) of PT Pertamina RU II Sungai Pakning, namely Peat Forest Honey Cultivation generated significant impact on social, economic, and environmental changes at the community level. Data on program implementation and outcome which were obtained through company implementation reports as well as telephone interviews with companies and beneficiaries are processed using Social Returns On Investment (SROI) method. The practice of forest beekeeping that minimizes the risk of land fires has succeeded in increasing livelihood of the beneficiaries and other stakeholders, as evidenced by the SROI result of 1.1. Beneficiaries' routines in carrying out the main job of producing honey and the capacity of beneficiaries to follow up on programs play an important role in the process of establishing impact values. This condition is created by the CSR intervention model that leads to environmentally friendly products, technological innovation, certification, and job creation. This study confirm the theory of doughnut economics and human capital.
\end{abstract}

Keywords: community empowerment, corporate social responsibility, doughnut economics, human capital, social return on investment

\section{Pendahuluan}

Pada saat sejumlah sarjana mempertemukan antara konsep Corporate Social Responsibility (CSR) dan pembangunan berkelanjutan (ElAlfy et al., 2020; Lu et al., 2021), nyatanya masih banyak pengukuran CSR yang kurang sesuai bahkan gagal dalam memaksimalkan keterlibatan strategis perusahaan untuk tujuan pembangunan berkelanjutan (Porter \& Kremer, 2006). Sehingga dalam konteks tersebut, Laba Sosial atas Investasi atau Social Return on Investment (SROI) sebagai sebuah metode dapat dimanfaatkan untuk memberikan evaluasi kelayakan program melalui perbandingan antara

\footnotetext{
${ }^{1}$ Departemen Pembangunan Sosial dan Kesejahteraan FISIPOL UGM (email korespondensi: rezaldi.a.p@ugm.ac.id)

${ }^{2}$ Departemen Pembangunan Sosial dan Kesejahteraan FISIPOL UGM (email: vandy@ugm.ac.id)

${ }^{3}$ PT Pertamina RU II Production Sungai Pakning (email: rudi@pertamina.com)

${ }^{4}$ PT Pertamina RU II Production Sungai Pakning (email: danny.prawijaya@pertamina.com)

${ }^{5}$ PT Pertamina RU II Production Sungai Pakning (email: rahmad.hidayat@pertamina.com)
} 
nilai manfaat yang tercipta dan biaya program yang sudah dikeluarkan oleh perusahaan.

Meskipun banyak dikritik karena hasil yang tidak terstandardisasi (Gibbon \& Dey, 2011a), inkonsistensi penghitungan (Watson et al., 2016), dan hasil yang meragukan (Luke etal., 2013), SROI tetap dianggap bermanfaat sebagai alat evaluasi karena fokus pada inklusi pemangku kepentingan (Whelan, 2015) serta kemampuannya dalam memberikan gambaran mengenai penciptaan dampak (Bellucci et al., 2019). Bermaksud untuk berupaya mengukur dampak sosial dan lingkungan selain juga dampak ekonomi, SROI merupakan aplikasi dari pendapat Galileo Galilei yang menyatakan "ukurlah apa yang dapat diukur dan buatlah menjadi bisa diukur sesuatu yang tidak bisa diukur". Setidaknya dengan berusaha mengukur, seseorang bisa menghindari hal yang jelas-jelas salah sebagaimana kalimat terkenal dari Carveth Read, "lebih baik samar-samar benar daripada jelas-jelas salah".

Hal yang penting dilakukan adalah bagaimana pengguna SROI menindaklanjuti hasil dari SROI. SROI cenderung memberikan hasil yang besar ketika penerima manfaat memiliki kemampuan untuk menindaklanjuti program. Jika merujuk ke sini, perusahaan yang mendasarkan perancangan program pada nilai SROI akan cenderung memiliki kelompok yang memiliki kapasitas tinggi (Vik, 2017). Padahal, untuk mewujudkan Social Development Goals (SDGs), keberpihakan kepada kelompok marjinal menjadi sangat mendesak untuk dilakukan.

Secara umum, SDGs 2030 dititikberatkan pada upaya sistematis dalam memberantas kemiskinan, ketidakadilan, dan perubahan iklim melalui pembangunan manusia yang berkelanjutan (Yakovleva et al., 2017). Dalam impelemantasinya, pemerintah manaruh harapan lebih pada inisiatif berbasis perusahaan, termasuk melalui CSR, agar dapat berperan strategis dalam pencapaian SDGs berbasis voluntary (Sheehy, 2015). Institusionalisasi SDGs ke dalam agenda CSR ini bahkan telah mengubah cara kerja tanggung jawab perusahaan terhadap mandat stakeholder dari yang sebelumnya cenderung reaktif menjadi lebih proaktif (ElAlfy \& Weber, 2019).

Rasionalisasi kegiatan produksi untuk menyeimbangkan dampak sosial, ekonomi, dan lingkungan yang sesuai tujuan dalam SDGs merupakan perubahan dalam konteks rantai pasok yang dapat terlacak. Pada aspek organisasional, telah banyak perusahaan yang memasukkan SDGs sebagai kerangka kerja di sejumlah fungsi yang sebelumnya tidak berkaitan, misalnya departemen hubungan masyarakat (Kemp, 2010). Pada titik ini, peran Multi-National Corporations (MNC) di negaranegara berkembang kiranya menjadi relevan, dimana perusahaan tidak hanya berperan menjadi perusak pembangunan namun sekaligus juga bagian dari solusi bagi upaya keberlanjutan; misalnya ketika kegiatan produksi melebihi daya dukung, konsekuanesinya produksi harus dikurangi, dampak lingkungan harus ditekan sampai titik maksimal melalui inovasi dan investasi (Mathuri, et al, 2012).

Bagibisnis, usaha untukmenginternalisasikan sejumlah persoalan kontemporer seperti yang tertuang dalam SDGs pada dasarnya berawal dari motif yang beragam, baik yang bersifat pragmatik maupun normatif (Muthuri et al., 2012: 360). Namun pada konteks studi ini, pembahasan tidak lagi berangkat dari motif perusahaan yang meletakkan SDGs ke dalam inisiatif mereka, melainkan lebih berupaya untuk mengukur dampak yang diperoleh dari inisiatif tersebut melalui SROI. Dengan mengambil kasus pada program CSR PT Pertamina RU II Sungai Pakning Riau Indonesia, artikel ini menyajikan hasil analisis perputaran investasi sosial yang telah dilakukan melalui salah satu program sustainability, yaitu Budidaya Madu Hutan Gambut yang dilaksanakan oleh kelompok Biene. Anggota kelompok Biene ini diberikan edukasi terlebih dahulu untuk tidak menggunakan asap dalam mengusir lebah dari sarangnya. Setelah mengikuti program, para pencari madu dari kelompok Biene kini mencari madu dengan menggunakan alat pelindung diri. Pencari madu kini tidak lagi menggunakan asap untuk mengusir lebah dari sarangnya. Di samping itu, para anggota juga didorong untuk membudidayakan lebah madu agar tidak lagi mencari madu di hutan. Program CSR ini menunjukkan bahwa meskipun kegiatan produktif yang ramah lingkungan memerlukan biaya produksi yang lebih besar, usaha pelestarian lingkungan mampu menghindarkan masyarakat dari kerugian akibat bencana lingkungan yang lebih besar. Terakhir, dengan menggunakan instrumen SROI, studi ini juga menganalisis peranan PT Pertamina RU II Sungai Pakning dan stakeholder lain dalam proses penciptaan dampak pada program CSR Budidaya Madu Hutan Gambut. 
Rezaldi Alief Pramadha, Vandy Yoga Swara, Rudi Hartono, D. Satria Wijaya, Rahmad Hidayat - Analisis Laba Sosial atas Investasi: Menyibak Asap Panen Madu Hutan Gambut untuk Kesejahteraan yang Lebih Cerah

\section{Kerangka Teori}

Dalam beberapa dekade terakhir, tren investasi pada bisnis yang bertanggung jawab secara sosial semakin meningkat (Renneboog et al., 2008). Perubahan lanskap kapitalisme ini menarik untuk ditelaah, khususnya pada pilihan pendekatan apa bisnis menjalankan misi sosialnya. Seperti misalnya Schoot and Frisher (1993) yang telah terlebih dahulu menganalisis ini dari sudut pandang organisasi, khususnya pada model strategi yang digunakan perusahaan dalam diskursus pembangunan berkelanjutan. Mereka menekankan pada pentingnya peneliti dalam bidang ini untuk memahami strategi bisnis yang digunakan untuk mengisi peranperan sosial perusahaan yang meliputi: kepatuhan (compliance driven) atau proaktif (proactive driven). Pada pendekatan proactive driven, perusahaan cenderung menempatkan stakeholder sebagai peluang investasi baru (Marín et al., 2012). Mengalokasikan sumber daya bisnis berbasis pada stakeholder demand adalah sebuah keputusan bisnis yang perlu diambil pada pendekatan ini (Kao et al., 2016). Konsekuensinya, aktivitas CSR akan berada dalam satu ruang dengan desain aktivitas investasi sosial yang dalam jangka panjang akan berdampak pada penyatuan tujuan ekonomi dan sosial perusahaan tanpa terlebih dahulu mempertentangkan keduanya (Porter and Kremer, 2002).

Pandangan ini percaya bahwa investasi ekonomi akan memberikan dampak signifikan secara sosial dan investasi sosial dapat kembali dalam bentuk performa ekonomi yang baik (Cochran, 2007). Konsekuensi strategi ini ialah bisnis harus merencanakan secara matang desain program yang akan mendatangkan economic and social return yang tinggi, yang oleh Cochran (2007) disebut sebagai community investment, di mana investasi perusahaan difokuskan kepada masyarakat dalam bentuk aktivitas nirlaba jangka panjang untuk tujuan memperkuat komunitas. Guna memperkuat cakupan dampak investasi sosial, pengukuran SROI diperlukan khususnya untuk mencari rasionaliasi peningkatan sumber daya yang dapat dialokasikan oleh perusahaan (Maier, 2015). Sebagaimana pondasi kelahirannya, analisis SROI berangkat dari teori ekonomi yang menekankan bahwa pengembalian sosial dari sebuah investasi dimaknai sebagai pengembalian internal (Canton, 2009), sehingga menjadi wajar apabila perusahaan berorientasi untuk meningkatkan nilai pengembalian dari aktivitas yang telah dirancang tersebut.

Keyakinan terhadap asumsi-asumsi kunci dalam SROI terkait penyematan nilai pasar sesuai dampak yang dirasakan oleh stakeholder (Gibbon \& Dey, 2011b), dapat diupayakan melalui pelaksanaan program CSR yang dapat menghasilkan network yang berkelanjutan berbasis jaringan pasar antara targeted group seperti masyarakat rentan dengan pemerinah maupun entitas bisnis yang lain (Mannan, 2009). Berangkat dari asumsi dasar pengembalian sosial, pendekatan human capital dalam CSR berperan penting dalam menjamin keberlanjutan dari inisiatif berbasis perusahaan. Pada titik ini penjelasan teoritik tentang modal manusia untuk dapat menciptakan penghasilan alternatif menjadi relevan, khususnya pada upaya penciptaan keterampilan dan teknologi untuk pertumbuhan (Kao et al., 2016). Orientasi utama dari pendekatan ini ialah penciptaan lapangan kerja tetap untuk mengelola risiko kemiskinan, sehingga fokus program CSR dalam konsep ini ialah pada peningkatan keterampilan melalui training, sertifikasi dan pengembangan teknologi. Dasar argumentasinya terletak pada kemiskinan yang dipandang sebagai kegagalan dalam memenuhi kebutuhan pengembangan modal manusia (Swinton, 1987). Dalam rangka mempersempit gap kebutuhan dan konteks ideal tersebut, CSR berperan penting sebagai inisiatif berbasis korporasi untuk meningkatkan human capital.

Selain strategi internal dan orientasi program, cakupan dampak dan isu juga menjadi faktor yang berkontribusi terhadap investasi sosial. Hal ini tidak terlepas dari semakin kompleksnya persoalan yang ada di berbagai level kehidupan masyarakat. Oleh karena itu, pembangunan berkelanjutan yang berfokus pada generasi saat ini dan masa mendatang (Todaro \& Smith, 2012), keseimbangan sosial dan lingkungan sebagai anti-tesis pembangunan pasca perang dunia (Mcmichael, 2014), produktivitas yang tampak dari kualitas hidup manusia dan lingkungan (Field \& Field, 2017; Raworth, 2017) perlu ditempatkan sebagai stakeholder demand (Kao et al., 2016) yang akan menentukan jenis aktivitas CSR perusahaan.

Dari pandangan ekonomi lingkungan, ketika kegiatan produksi melebihi daya dukung lingkungan, akan terjadi kerusakan yang 
merugikan masyarakat luas. Masyarakat perlu mengeluarkan biaya untuk mengatasi kerusakan yang ditimbulkan dari kegiatan produksi dari pihak lain. Pada gilirannya, hal ini menyebabkan turunnya kesejahteraan masyarakat secara keseluruhan. Artinya, diperlukan pembatasan agar pelaku usaha berproduksi sesuai daya dukung lingkungan. Penanganan permasalahan ini menurut model ekonomi adalah dengan menginternalisasi eksternalitas negatif tersebut. Internalisasi eksternalitas dapat dilakukan dengan membuat inovasi proses produksi yang ramah lingkungan, penetapan regulasi, atau pajak polusi (Field \& Field, 2017). Berbagai solusi yang ditawarkan bermuara pada penyesuaian skala produksi oleh pelaku usaha. Di sisi lain solusi ini memiliki konsekuensi pada menurunnya produksi output secara keseluruhan.

Di balik pandangan optimis yang menggambarkan pembangunan berkelanjutan, konsep ini juga dikritik karena ambiguitasnya, terutama pada pertanyaan dilematis seperti bagaimana mempertahankan pertumbuhan dalam jangka panjang di sebuah planet yang terbatas (Ruggerio, 2021). Pandangan ini kemudian melahirkan ide absolute decoupling dan relative decoupling (Haberl et al., 2020). Pada absolute decoupling, kualitas lingkungan dipertahankan ketika melaksanakan pembangunan. Sedangkan pada relative decoupling, pembangunan dilaksanakan dengan tingkat penurunan kualitas lingkungan yang lebih rendah. Pada tingkatan yang lebih ekstrim, gagasan degrowth dan buen vivir muncul sebagai alternatif untuk mempertahankan kualitas lingkungan dan memperbaiki struktur sosial masyarakat (Kothari et al., 2014).

Dalam menjembatani keseimbangan di dalam dimensi pembangunan berkelanjutan, Enviromental Kuznet Curve (EKC) dapat dijadikan rujukan dalam melakukan proyeksi model pertumbuhan dan pembangunan sosial ekonomi yang dapat sejalan dengan peningkatan kualitas lingkungan. Studi Feng et al. (2017), pada data panel Indeks Pembangunan Hijau dengan menggunakan $E K C$ untuk menggambarkan kondisi di 165 negara telah menunjukkan bahwa titik balik kurva berada pada saat GDP per kapita mencapai US\$ 2424. Standard itu kemudian menjadi tolok ukur disparitas negara maju dan berkembang sejak awal abad 21. Adeleke dan Josue (2019) dengan menggunakan Auto Regressive Distributed Lag, menunjukkan bahwa pembangunan ekonomi yang ramah lingkungan memiliki dampak yang lebih besar pada jangka panjang dibandingkan jangka pendek. Pada jangka panjang, perekonomian akan terhindar dari bencana lingkungan yang mungkin terjadi ketika proses produksi dilakukan tanpa pertimbangan lingkungan.

\section{Gambar 1 Model Doughnut Economics}

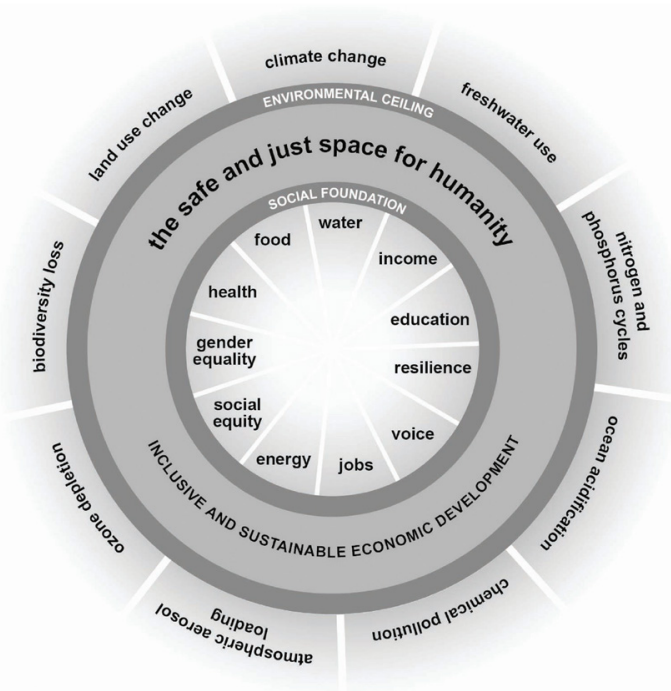

Sumber: Raworth (2017)

Kate Raworth (2017) mengusulkan model Doughnut Economics (Ekonomi Donat) untuk mewujudkan pembangunan berkelanjutan. Sebagaimana donat yang berlubang di tengah, model ini menempatkan batas sosial di lingkaran dalam dan batas lingkungan di sisi luar donat. Pembangunan menurut argumen Raworth, sebaiknya tidak lagi dipandang sebagai usaha mendorong pertumbuhan setinggi mungkin namun lebih pada mewujudkan keseimbangan antara kelayakan kehidupan manusia dengan batas kapasitas ekologis. Di bawah batas sosial di lingkaran dalam donat adalah kondisi kekurangan pada sebelas aspek mulai dari pangan, kesehatan, pendidikan, pendapatan dan pekerjaan, kedamaian dan keadilan, aspirasi politik, keadilan sosial, kesetaraan gender, perumahan, jaringan, energi, dan air. Programprogram pembangunan ditujukan untuk dapat mencukupi dan memperbaiki kondisi pada sebelas aspek tersebut agar masyarakat memiliki tingkat kehidupan yang lebih baik.

Di sisi luar donat, terdapat batas plafon ekologi yang jika dilewati akan merusak kualitas lingkungan bumi. Terdapat sembilan 
Rezaldi Alief Pramadha, Vandy Yoga Swara, Rudi Hartono, D. Satria Wijaya, Rahmad Hidayat - Analisis Laba Sosial atas Investasi: Menyibak Asap Panen Madu Hutan Gambut untuk Kesejahteraan yang Lebih Cerah

bentuk penurunan kualitas lingkungan ketika pembangunan melebihi plafon ekologi, yaitu perubahan iklim, pengasaman laut, polusi kimia, muatan nitroen dan fosfor, penggunaan air tanah, konversi lahan, keanekaragaman hayati, polusi udara, dan penipisan lapisan ozon. Model ekonomi donat ini menerjemahkan ide pembangunan berkelanjutan dengan memberikan batasan sosial dan lingkungan secara riil. Kehidupan yang adil dan damai terletak di antara dua batas pondasi sosial dan plafon ekologi (Raworth, 2017). Lebih lanjut, Raworth juga mengatakan bahwa untuk merealisasikan model ekonomi donat, salah satunya dibutuhkan usaha untuk meredistribusi kesejahteraan secara sengaja. Sehinga sangat diperlukan intervensi untuk memperbaiki kondisi masyarakat alih-alih hanya menyerahkan pada mekanisme pasar.

Sektor privat melalui CSR dan kapasitasnya dalam memobilisasi sumber daya dalam jumlah besar dan kualitas tinggi akan berkontribusi besar untuk pencapaian SDGs (Fordham \& Robinson, 2019). Sebagaimana Kumi et al (2020) dalam tinjauannya pada kontribusi CSR terhadap SDGs negara berkembang menunjukkan sejumlah karakteristik, misalnya CSR bersifat jangka pendek, tidak melibatkan stakeholder secara optimal namun potensial untuk dikembangkan. Dalam batasan tertentu, karakteristik tersebut terjadi di Indonesia. Di satu sisi CSR tetaplah standar praktik bisnis, namun pada sisi lain pada perkembangannya CSR bekerja semakin holistik dalam mencapai kebutuhan yang berkelanjutan. Pada titik inilah perusahaan mulai melibatkan pemangku kepentingannya untuk mengaktiviasi sumber daya masyarakat dalam rangka mencapai hasil sosial-lingkungan jangka panjang dan berkelanjutan (Pesmatzoglou et al., 2014). Di luar dari motif dasarnya, perluasan makna dan praktik CSR ini menarik untuk diulas dalam kerangka pembuktian. Dengan demikian, artikel ini berupaya untuk menyajikan satu fakta praktik CSR dalam tinjauan SROI untuk mengetahui seberapa besar kontribusi CSR terhadap sejumlah indikator pembangunan berkelanjutan atau SDGs pada stakeholder di level mikro.

\section{Metode Penelitian}

Studi ini menggunakan metode penelitian kuantitatif yang mendasarkannya pada metode analisis SROI (Nicholls et al., 2012). SROI dihitung dengan cara membandingkan nilai sekarang (present value) perubahan pada aspek ekonomi, sosial, dan lingkungan terhadap nilai investasi suatu program intervensi. Nilai SROI berkisar dari kurang dari nol sampai lebih dari nol. SROI kurang dari nol berarti bahwa program menghasilkan perubahan negatif, sedangkan SROI lebih dari nol menunjukkan bawa program menghasilkan perubahan positif. Lebih detail, ketika SROI bernilai positif antara nol dan satu, program menghasilkan perubahan positif namun masih lebih rendah daripada nilai investasi. Ketika nilai SROI lebih dari satu, nilai perubahan akibat program lebih dari nilai investasi.

Terdapat lima tahapan penghitungan SROI, yaitu penentuan pemangku kepentingan, memahami perubahan yang terjadi, pembuktian dan pemberian nilai pada perubahan, fiksasi dampak, dan perhitungan SROI. Dengan mengikuti lima tahapan ini, SROI memberi peluang kepada peneliti untuk mengubah nilai manfaat ke dalam bentuk nilai mata uang (monetisasi) sehingga pada akhirnya, nilai manfaat dapat dibandingkan dengan nilai investasi program.

Lebih dalam dari pada itu, proses penghitungan SROI ini juga dilengkapi dengan proses fiksasi dampak untuk menghindarkan hasil penghitungan dari risiko overclaim. Fiksasi dampak dilakukan dengan mengidentifikasi empat poin, yaitu deadweight, attribution, displacement, dan drop-off. Setelah itu, penghitungan SROI memasukkan proses penghitungan present value untuk menyesuaikan nilai perubahan yang terjadi pada tahun setelah pelaksanaan intervensi. Present value dihitung dengan tingkat diskonto 3,5\% per tahun sesuai dengan ketentuan SROI untuk program sosial.

Adapun data yang digunakan pada penelitian ini adalah data sekunder mengenai implementasi program yang disusun oleh perusahaan serta data primer yang dikumpulkan melalui wawancara telepon kepada perwakilan perusahaan dan perwakilan anggota kelompok (penerima manfaat program) pada bulan Juli 2020. Langkah ini diambil sebagai bentuk adaptasi penelitian pada masa pandemi. Penggalian data dan informasi terkait kondisi anggota kelompok yang lain dilakukan melalui wawancara kepada informan kunci tersebut. Tanpa observasi lapangan secara langsung, 
penelitian ini dihadapkan pada kendala menangkap kondisi lingkungan yang riil. Guna mengatasi hal tersebut, proses wawancara juga mencakup penggalian informasi mengenai kondisi lingkungan dan sosial penerima manfaat. Informan yang dilibatkan ditentukan menggunakan metode purposive sampling di mana informan yang dipilih adalah mereka yang terlibat dan memahami pelaksanaan program serta para penerima manfaat program yang terdampak oleh pelaksanaan program secara langsung maupun tidak langsung.

\section{Hasil}

Program yang dianalisis dalam studi ini adalah Program Budidaya Madu Hutan Gambut yang dilaksanakan oleh PT Pertamina RU II Sungai Pakning di wilayah Bengkalis Desa Tanjung Leban, Kecamatan Bandar Laksamana. Program CSR ini dilatarbelakangi oleh kondisi masyarakat sekitar yang memiliki mata pencaharian sebagai pencari madu tradisonal. Di sisi lain, kegiatan pencarian madu secara tradisional ini berisiko menimbulkan kebakaran lahan karena penggunaan asap untuk mengusir lebah.

Proses pencarian madu secara tradisional biasanya dilakukan secara berkelompok oleh tiga orang atau lebih. Tim pencari madu ini akan masuk ke hutan untuk mencari sarang lebah yang siap dipanen. Setelah menemukan sarang lebah, salah satu anggota tim bertugas membuat asap dengan membakar dahan kering untuk mengusir lebah. Setelah lebah pergi dari sarang, satu anggota akan mendekati sarang dan menjatuhkan sarang agar bisa dibawa oleh anggota tim yang bertugas menerima sarang. Jika jumlah sarang sudah cukup, mereka akan kembali ke rumah dan memanen madu yang ada di sarang. Setelah itu kemudian madu dimasukkan ke dalam wadah botol yang disebut kati. Seringkali setelah menggunakan dahan kering yang dibakar, pencari madu tidak mematikan apinya. Hal ini berisiko menyebabkan kebakaran lahan ketika musim kering.

Pertamina Sungai Pakning kemudian melaksanakan program CSR yang fokus pada pencegahan kebakaran lahan akibat aktivitas pencarian madu ini. Mulai tahun 2019, Pertamina Sungai Pakning menyelenggarakan program penyuluhan dan edukasi kepada kelompok pencari madu Biene. Kegiatan ini diikuti dengan pelatihan budidaya madu, sertifikasi PIRT, dan pembuatan sarana budidaya madu.
Setelah didampingi oleh Pertamina Sungai Pakning, pencari madu hutan dari kelompok Biene tidak lagi menggunakan asap untuk mengusir madu dari sarangnya. Anggota kelompok kini mencari madu dengan menggunakan alat pelindung diri untuk mencegah sengatan lebah. Cara yang baru ini dirasakan lebih ramah lingkungan dan tidak berisiko pada kebakaran lahan. Di sisi lain, penggunaan alat pelindung diri ini berimplikasi pada tambahan biaya produksi. Setiap anggota harus mengeluarkan Rp300.000,- setiap tiga bulan untuk membeli baju pelindung.

Pelaksanaan program pendampingan dari Pertamina Sungai Pakning juga berdampak pada produksi dan pendapatan kelompok pencari madu hutan Biene. Setelah dihubungkan dengan Rumah Madu Wilbi di Kabupaten Kampar, pencari madu kini bisa mencari madu setiap hari dan memiliki tujuan pemasaran yang pasti. Pada gilirannya, hal ini meningkatkan produksi dan pendapatan anggota kelompok dibandingkan sebelum didampingi oleh Pertamina Sungai Pakning. Sebelumnya, anggota kelompok hanya mencari madu ketika ada permintaan saja sehingga pendapatan tidak pasti.

Guna meningkatkan stabilitas usaha madu, Pertamina Sungai Pakning juga memberi pelatihan dan fasilitasi budidaya madu hutan gambut. Adanya pelatihan dan fasilitasi ini ditindaklanjuti oleh anggota kelompok dengan menjalankan usaha budidaya madu. Selain menghasilkan madu, kegiatan budidaya juga menghasilkan lilin dari sarang lebah yang juga bisa dijual. Sampai bulan juli 2020, seluruh anggota sudah menjalankan budidaya namun baru satu anggota yang sudah menghasilkan pendapatan dari budidaya madu ini. Pendapatan yang muncul dari budidaya madu ini kemudian menarik minat rekan anggota kelompok budidaya madu. Rekan di luar kelompok ini mempelajari teknik budidaya madu dari anggota kelompok Wilbi dan mendirikan usaha budidaya madu secara mandiri.

Selain itu, Pertamina Sungai Pakning juga mendorong kelompok untuk menikmati nilai tambah yang lebih besar dari proses produksi madu melalui fasilitasi pengolahan madu menjadi madu kemasan sampai ke pendfataran PIRT. Produk jadi yang diproduksi mampu memperluas sumber pendapatan kelompok pencari madu. Selanjutnya akan dijelaskan perincian detail program berdasarkan aspek- 
Rezaldi Alief Pramadha, Vandy Yoga Swara, Rudi Hartono, D. Satria Wijaya, Rahmad Hidayat - Analisis Laba Sosial atas Investasi: Menyibak Asap Panen Madu Hutan Gambut untuk Kesejahteraan yang Lebih Cerah

Tabel 1

Kegiatan pada Program Budidaya Madu Hutan Gambut

\begin{tabular}{|c|c|c|c|c|}
\hline No. & Kegiatan & Waktu & Biaya & Present Value \\
\hline 1. & $\begin{array}{l}\text { Penyuluhan \& Edukasi Madu } \\
\text { Hutan Ramah Lingkungan }\end{array}$ & Tanjung Leban, 24 April 2019 & Rp25.000.000,- & Rp25.000.000,- \\
\hline 2. & $\begin{array}{l}\text { Pelatihan Budidaya Madu Tingkat } \\
\text { Dasar }\end{array}$ & Kuok, 19 Agustus 2019 & Rp35.000.000,- & Rp35.000.000,- \\
\hline 3. & Standarisasi PIRT & $\begin{array}{l}\text { Tanjung Leban, } 20 \text { September } \\
2019\end{array}$ & Rp10.000.000,- & Rp10.000.000,- \\
\hline 4. & Pembuatan Sarana Budidaya Madu & Tanjung Leban, 11 Maret 2020 & Rp50.000.000,- & Rp48.076.923,08,- \\
\hline
\end{tabular}

Sumber: Pertamina Sungai Pakning, 2020

Tabel 2

Identifikasi Outcome yang Proses Penciptaan Dampak yang Dialami Setiap Stakeholder

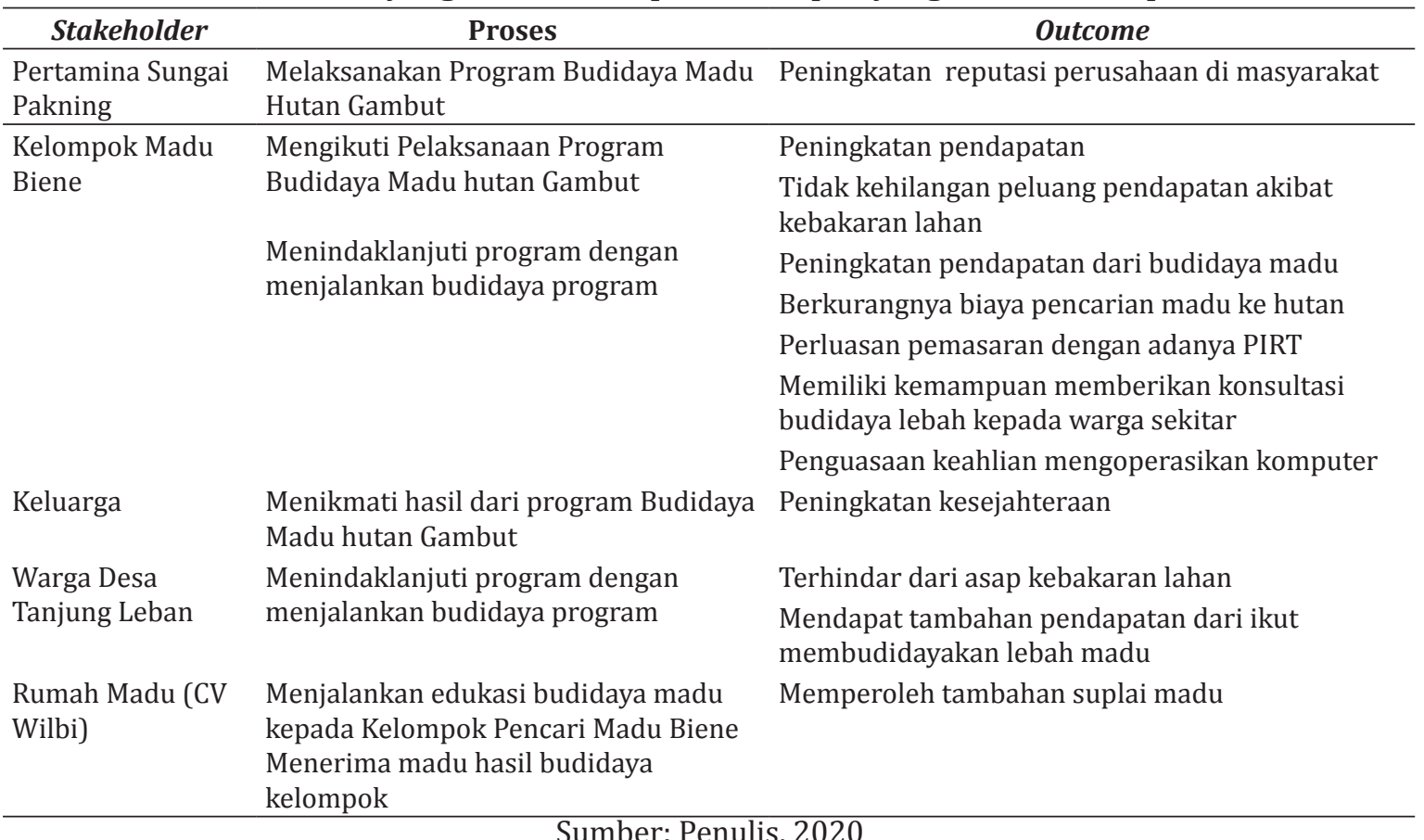

Sumber: Penulis, 2020

aspek pada SROI yaitu input yang digunakan, kegiatan yang dilaksanakan, output yang dihasilkan, dampak yang tercipta, serta metode monetisasi yang digunakan.

Pada tabel 1, dapat dilihat bahwa nilai investasi kegiatan dikonversi ke dalam present value. Hal ini dilakukan karena rangkaian kegiatan dilakukan pada tahun yang berbeda mulai 2019 sampai 2020. Untuk memperoleh nilai riil yang sesuai, maka nilai kegiatan tahun 2020 dikonversi ke present value tahun 2019.

Tahap pertama dari SROI adalah mengidentifikasi stakeholder dari pelaksanaan program. Studi ini mengidentifikasi lima stakeholder program dengan bentuk outcome yang berbeda-beda. Stakeholder yang diidentifikasi dari program ini adalah Pertamina Sungai Pakning, Kelompok Pencari Madu Biene, Keluarga, warga Desa Tanjung Leban, dan Rumah Madu Wilbi. Dapat dilihat pada tabel 2 bahwa setiap stakeholder menjalani proses penciptaan dampak. Terdapat kontribusi yang dilakukan oleh Kelompok Pencari Madu Biene, Warga Tanjung Leban, dan Rumah Madu Wilbi dalam program ini. Maka, nilai kontribusi mereka perlu diperhitungkan dalam proses penghitungan SROI.

Proses penghitungan SROI dilanjutkan ke proses pembuktian dampak dan pemberian nilai. Pada tahap ini, setiap outcome yang diidentifikasi akan dibuktikan dengan narasi yang menunjukkan adanya perubahan. Nilai 
Tabel 3

Nilai kontribusi Stakeholder Program dalam Proses Penciptaan Dampak

\begin{tabular}{|c|c|c|c|c|}
\hline No. & Kegiatan & Waktu & Biaya & Present Value \\
\hline 1. & $\begin{array}{l}\text { Pengelolaan Usaha Budidaya Madu oleh } \\
\text { satu orang anggota kelompok }\end{array}$ & $\begin{array}{l}\text { Oktober 2019-Deseber } \\
2019\end{array}$ & Rp4.500.000,- & Rp4.500.000,- \\
\hline 2. & $\begin{array}{l}\text { Pengelolaan Usaha Budidaya Madu oleh } \\
\text { Anggota kelompok dan rekan }\end{array}$ & Januari Agustus 2020 & Rp24.000.000,- & Rp23.076.923,08,- \\
\hline 3. & $\begin{array}{l}\text { Pendirian usaha budidaya madu oleh } \\
\text { rekan anggota kelompok }\end{array}$ & Januari 2020 & Rp100.000.000,- & Rp96.153.846,15,- \\
\hline 4. & Pelatihan oleh Rumah Madu Wilbi & 2019 & Rp6.000.000,- & Rp6.000.000,- \\
\hline 5. & Pelatihan oleh Rumah Madu Wilbi & 2020 & Rp3.000.000,- & Rp2.898.550,72,- \\
\hline
\end{tabular}

Sumber: Penulis, 2020

Tabel 4

Pembuktian Outcome dan Pemberian Nilai

\begin{tabular}{|c|c|}
\hline Outcome & Pembuktian \\
\hline $\begin{array}{l}\text { Peningkatan reputasi } \\
\text { perusahaan di masyarakat }\end{array}$ & $\begin{array}{l}\text { Pertamina sudah memiliki hubungan } \\
\text { baik dengan warga sehingga adanya } \\
\text { program ini tidak berdampak signifikan } \\
\text { pada peningkatan kualitas hubungan } \\
\text { dengan warga. }\end{array}$ \\
\hline
\end{tabular}

Peningkatan pendapatan 4 orang anggota kelompok merasakan peningkatan pendapatan pada tahun 2019

6 orang anggota kelompok merasakan peningkatan pendapatan pada tahun 2020.

Tidak kehilangan peluang 4 orang anggota kelompok merasakan pendapatan akibat kebakaran lahan tidak adanya kehilangan pendapatan pada tahun 2019.

6 orang anggota kelompok merasakan tidak adanya kehilangan pendapatan pada tahun 2020 .

Peningkatan pendapatan dari budidaya madu

Berkurangnya biaya pencarian madu ke hutan

Perluasan pemasaran dengan adanya PIRT
1 orang anggota kelompok merasakan peningkatan pendapatan dari budidaya madu mulai oktober 2019.

1 orang anggota kelompok merasakan peningkatan pendapatan dari budidaya madu pada tahun 2020 dari januari sampai agustus.

1 orang anggota kelompok merasakan peningkatan pendapatan dari penjualan lilin lebah mulai oktober 2019.

1 orang anggota kelompok merasakan peningkatan pendapatan dari penjualan lilin lebah pada tahun 2020 dari januari sampai agustus.

1 orang anggota kelompok merasakan peningkatan pendapatan dari budidaya madu pada tahun 2020.

Kelompok mampu memasarkan produk madu olahan sendiri.
Pendapatan bersih yang diperoleh setelah adanya program adalah sebesar Rp2,5 juta per bulan per orang. Sebelumnya, pendapatan dari mencari madu hanya Rp 1juta karena hanya menunggu permintaan.

Jika terjadi kebakaran karena asap pencarian madu, kegiatan pencarian madu dapat terhenti selama satu bulan. Hal ini membuat petani madu kehilangan pendapatan selama 1 bulan. Berdasarkan pengalaman sebelumnya, kebakaran karena asap pencarian madu biasanya terjadi 1 tahun sekali selama 1 bulan. Pendapatan yang terancam hilang setelah adanya program $\mathrm{Rp} 2,5$ juta

Budidaya madu dari 10 sarang menghasilkan 2-3 kati per bulan dengan harga per kati Rp 100ribu pada tahun 2019.

Sejak Mei 2020 mampu panen dari 50 sarang.

Setiap bulan, budidaya lebah menghasilkan $10 \mathrm{~kg}$ lilin dengan harga jual Rp50ribu per kg lilin.

Proses mencari madu ke hutan memerlukan biaya baju pelindung yang harus berganti 3 bulan sekali. Harga setiap baju pelindung Rp 300 ribu.

Kelompok mampu menjual 467 botol madu ke Pertamina dengan keuntungan Rp6000 per botol. 
Rezaldi Alief Pramadha, Vandy Yoga Swara, Rudi Hartono, D. Satria Wijaya, Rahmad Hidayat - Analisis Laba Sosial atas Investasi: Menyibak Asap Panen Madu Hutan Gambut untuk Kesejahteraan yang Lebih Cerah

\begin{tabular}{|c|c|c|}
\hline Outcome & Pembuktian & Pemberian Nilai \\
\hline $\begin{array}{l}\text { Memiliki kemampuan } \\
\text { memberikan konsultasi } \\
\text { budidaya lebah kepada } \\
\text { warga sekitar }\end{array}$ & $\begin{array}{l}2 \text { orang anggota kelompok mampu } \\
\text { mengoperasikan komputer setelah ada } \\
\text { bantuan dari Pertamina. }\end{array}$ & $\begin{array}{l}\text { Kemampuan baru dalam mengoperasikan } \\
\text { komputer setara dengan kursus komputer } \\
\text { Rp500ribu per orang di daerah Bengkalis . }\end{array}$ \\
\hline $\begin{array}{l}\text { Peningkatan } \\
\text { kesejahteraan }\end{array}$ & $\begin{array}{l}\text { (sudah terakomodasi dalam peningkatan } \\
\text { pendapatan anggota kelompok madu) }\end{array}$ & - \\
\hline $\begin{array}{l}\text { Terhindar dari asap } \\
\text { kebakaran lahan }\end{array}$ & $\begin{array}{l}\text { Tidak signifikan karena asap tidak } \\
\text { sampai ke pemukiman warga. }\end{array}$ & - \\
\hline $\begin{array}{l}\text { Mendapat tambahan } \\
\text { pendapatan dari ikut } \\
\text { membudidayakan lebah } \\
\text { madu }\end{array}$ & $\begin{array}{l}1 \text { orang memperoleh pendapatan } \\
\text { tambahan dari ikut membudidayakan } \\
\text { lebah madu sebanyak } 110 \text { sarang. }\end{array}$ & $\begin{array}{l}\text { Budidaya madu dari } 10 \text { sarang } \\
\text { menghasilkan 2-3 kati per bulan dengan } \\
\text { harga per kati Rp 100ribu. }\end{array}$ \\
\hline $\begin{array}{l}\text { Memperoleh tambahan } \\
\text { suplai madu }\end{array}$ & $\begin{array}{l}\text { CV Wilbi memperoleh tambahan supplai } \\
\text { madu. Namun supplai ini tidak signifikan } \\
\text { karena CV Wilbi sudah memiliki sistem } \\
\text { produksi yang stabil. }\end{array}$ & $\begin{array}{l}\text { Suplai madu dari kelompok Biene tidak } \\
\text { berpengaruh signifikan pada produksi } \\
\text { madu CV Wilbi. }\end{array}$ \\
\hline
\end{tabular}

Sumber: Penulis, 2020

perubahan lalu menjadi dasar untuk proses pemberian nilai atau monetisasi. Besaran perubahan akan dikalikan dengan metode monetisasi yang dinilai paling sesuai.

\section{Fiksasi Dampak}

Penciptaan dampak pada program ini diikuti oleh displacement dalam bentuk pengeluaran biaya untuk perlengkapan pengaman mencari madu dan drop off dalam bentuk berkurangnya pendapatan dari mencari madu di hutan oleh satu orang anggota setelah anggota ini menjalankan usaha budidaya lebah madu. Biaya perlengkapan pengaman Rp300ribu dan dikeluarkan setiap 3 bulan sekali. Untuk intensitas mencari madu di hutan berkurang 50 persen dari mencari madu di hutan pada tahun 2020 untuk 1 orang anggota. Komponen pengurang tersebut dimasukkan ke dalam proses penghitungan SROI dengan nilai negatif.

\section{Penghitungan SROI}

$$
S R O I=\frac{R p 276.060 .144,93}{R p 251.514 .493}=1,1
$$

Hasil penghitungan SROI menunjukkan bahwa Program Budidaya Madu Hutan Gambut bernilai 1,1. Angka tersebut berarti bahwa untuk setiap Rp1 biaya program yang dikeluarkan menghasilkan manfaat senilai Rp1,1. Nilai yang positif dan lebih dari satu menunjukkan bahwa manfaat yang dihasilkan dari program ini lebih besar daripada biaya yang dikeluarkan.
Tabel 5

Hasil Penghitungan Nilai Monetisasi Manfaat dan Present Value

\begin{tabular}{lc}
\hline \multicolumn{1}{c}{ Dampak } & \multicolumn{1}{c}{ Subtotal } \\
\hline Biaya baju pelindung & -Rp8.629.061,87 \\
$\begin{array}{l}\text { Peningkatan pendapatan } \\
\begin{array}{l}\text { Penanganan risiko kehilangan } \\
\text { pendapatan }\end{array}\end{array}$ & $\mathrm{Rp} 115.054 .158,25$ \\
Rp23.969.616,30
\end{tabular}

Tambahan pendapatan dari

Madu budidaya

Rp21.112.539,01

Tambahan pendapatan dari produksi lilin

Rp5.278.134,75

Penghematan pelindung

Rp576.923,08

Pengurangan pendapatan dari masuk hutan

-Rp13.195.336,88

Kemampuan Mengoperasikan

komputer

Rp954.653,94

pemasukan dari madu olahan

sendiri

Rp2.694.230,77

konsultasi ternak lebah madu fulltime

Rp1.442.307,69

Tambahan pendapatan dari budidaya madu

$\operatorname{Rp} 38.461 .538,46$

Tambahan pendapatan dari budidaya madu oleh rekan

Rp84.615.384,62 anggota kelompok

Rp276.060.144,93

Sumber: Penulis, 2020

\section{Analisis Sensitivitas}

Analisis sensitivitas dilakukan untuk melihat nilai perubahan SROI ketika terjadi perubahan kondisi yang mungkin terjadi. Pada program ini, perubahan yang mungkin terjadi adalah tidak terjadinya penyebaran budidaya madu dari anggota kelompok ke rekan anggota. Ketika 
hal tersebut terjadi, nilai SROI naik menjadi 1,23. Ketika nilai suku bunga naik $10 \%$ karena perubahan kondisi, nilai SROI tidak berubah dari 1,1.

\section{Diskusi}

Hasil penghitungan SROI menunjukkan bahwa Program Budidaya Madu Hutan Gambut oleh Pertamina Sungai Pakning di kelompok pencari madu Biene menghasilkan pengaruh positif. Dampak positif bersumber dari proses pelatihan, dukungan peralatan, perluasan jaringan pemasaran, dan dukungan usaha budidaya. Kegiatan yang dilaksanakan dalam program tersebut kemudian ditindakanlanjuti penerima manfaat dengan kegiatan pencarian madu yang ramah lingkungan serta penjualan madu yang lebih stabil setiap harinya. Pencarian madu yang ramah lingkungan dilakukan dengan cara menggunakan alat pelindung diri untuk menghindari sengatan lebah alih-alih menggunakan asap. Kemudian penjualan madu yang lebih konsisten setiap harinya diperoleh dari pengambangan jaringan penjualan dengan Rumah Madu Wilbi. Manfaat positif lain adalah terhindarnya pencari lebah dari hilangnya potensi pendapatan ketika terjadi kebakaran lahan akibat penggunaan asap selama satu bulan setiap tahunnya. Manfaat lain yang muncul adalah usaha budidaya lebah yang dilakukan oleh salah satu anggota dan rekan di luar kelompok.

Dilihat dari hasil penghitungan nilai manfaat, biaya tambahan untuk membeli alat pelindung diri lebih kecil daripada risiko kehilangan pendapatan akibat kebakaran lahan yaitu sebesar Rp8,6 juta dibandingkan Rp23,9 juta berturut-turut. Jadi, pencarian madu dengan metode yang ramah lingkungan lebih menguntungkan daripada sebelumnya. Pencari madu kini dapat mencari madu sepanjang tahun tanpa terhambat kebakaran lahan. Bagi masyarakat lain, tidak adanya kasus kebakaran lahan juga merupakan manfaat yang besar karena terhindar dari gangguan kesehatan dan gangguan aktivitas lain. Namun demikian, manfaat sosial dan lingkungan dari tidak adanya kebakaran lahan tidak diklaim dalam penelitian ini karena jarak yang jauh dari pemukiman sehingga tidak signifikan.

Hasil tersebut menunjukkan bahwa program ini mampu meningkatkan kualitas kehidupan anggota kelompok lebih tinggi dari batas sosial dan tidak membahayakan secara ekologi sebagaimana model ekonomi donat. Pencarian madu yang tidak menggunakan asap menghindakan lingkungan hutan dari bahaya kebakaran lahan. Terjadinya kebakaran akan menyebabkan penurunan kualitas lingkungan pada sembilan aspek yang disebutkan dalam model donat. Kebakaran lahan akan memperparah perubahan iklim, merusak kualitas air tanah di lahan gambut, penipisan lapisan ozon, sampai pada penurunan keanekaragaman hayati.

Lebih lanjut, sebagaimana pendapat Raworth (2017), usaha menjaga lingkungan mampu menghindarkan anggota kelompok dari penurunan kondisi sosial. Tanpa kebakaran lahan, pencari madu bisa tetap mampu mencari madu hutan sepanjang tahun. Dengan demikian, program ini berhasil meningkatkan kualitas hidup anggota kelompok Biene sebagai penerima manfaat program. Anggota kelompok merasakan peningkatan pendapatan sebagai dampak yang paling besar. Selain itu, meskipun tidak dirasakan secara signifikan, tidak adanya kebakaran lahan berkontribusi pada terjaganya aspek sosial kehidupan anggota kelompok.

Pada sisi edukasi, Pertamina Sungai Pakning memainkan peranan penting dalam mengenalkan metode pencarian madu yang ramah lingkungan dan tidak berisiko menyebabkan kebakaran lahan. Pengetahuan yang dimiliki oleh Pertamina Sungai Pakning mengenai bahaya kebakaran lahan disampaikan kepada kelompok pencari madu Biene. Selain itu, Pertamina Sungai Pakning juga menginisiasi penggunaan alat pelindung diri untuk mencari madu. Pertamina Sungai Pakning tidak hanya menyadarkan kelompok mengenai risiko namun juga memberi solusi agar kelompok tetap bisa menjalankan usahanya. Langkah ini kemudian diperkuat juga dengan fasilitasi usaha budidaya lebah madu.

Fakta ini mengonfirmasi pendapat Kuznet bahwa kemiskinan berdampak negatif terhadap lingkungan. Penggunaan asap untuk mengusir lebah adalah cara kelompok masyarakat miskin untuk memperoleh pendapatan. Keterbatasan sumber daya dan kapasitas menyebabkan mereka mencari pendapatan dengan peralatan seadanya tanpa mampu mengusahakan metode yang lebih baik. Kerja sama yang digagas Pertamina Sungai Pakning dan Kelompok Pencari Madu Biene berhasil melepaskan kelompok dari metode pencarian madu yang membahayakan lingkungan. 
Rezaldi Alief Pramadha, Vandy Yoga Swara, Rudi Hartono, D. Satria Wijaya, Rahmad Hidayat - Analisis Laba Sosial atas Investasi: Menyibak Asap Panen Madu Hutan Gambut untuk Kesejahteraan yang Lebih Cerah

\section{Gambar 2 \\ Persentase Bentuk Manfaat Program Budidaya Madu Hutan Gambut}

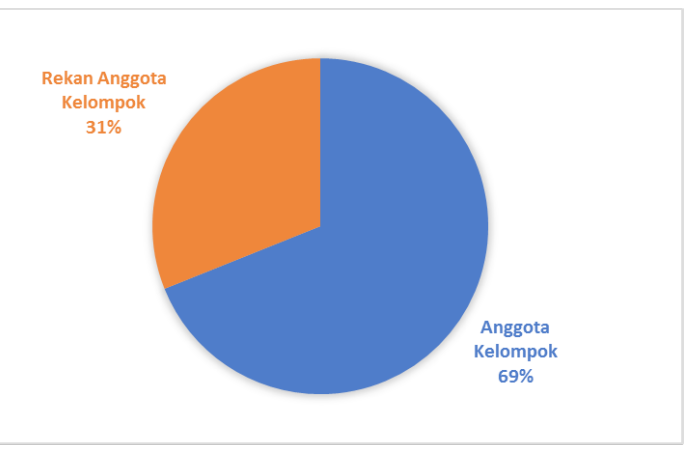

Sumber: Penulis, 2020

Gambar 2 menunjukkan persentase manfaat Program Budidaya Madu hutan Gambut. Peningkatan pendapatan menjadi bentuk manfaat terbesar (36 persen) diikuti tambahan pendapatan dari budidaya madu yang dijalankan rekan anggota (27 persen), tambahan pendapatan dari budidaya madu (12\%), dan penanganan risiko kehilangan pendapatan (8\%). Hal ini menunjukkan bahwa manfaat terbesar diperoleh dari intensitas tindak lanjut program oleh penerima manfaat. Pada program ini, pemberdayaan kepada pencari madu hutan menghasilkan manfaat yang besar dalam hal pendapatan dari kegiatan pencarian madu yang dilakukan setiap hari serta usaha budidaya madu.

Dari grafik tersebut, juga dapat dipahami bahwa usaha implementasi pencarian madu ramah lingkungan berpengaruh positif pada pendapatan anggota kelompok. Peningkatan produksi dapat dilakukan oleh kelompok karena ada Rumah Madu Wilbi yang selalu dapat menyerap produksi madu dari kelompok Biene. Peningkatan produksi pada kegiatan pencarian madu oleh kelompok tidak menimbulkan kerusakan lingkungan. Perlu dipahami di sini bahwa produksi madu oleh kelompok Biene selama ini masih di bawah daya dukung lingkungan. Ketika Pertamina Sungai Pakning menghubungkan kelompok dengan rumah madu Wilbi, peningkatan produksi yang dilakukan kelompok tidak sampai mengganggu daya dukung lingkungan.
Selanjutnya, penciptaan dampak yang besar diraih melalui kesesuaian program dengan kegiatan usaha yang menjadi mata pencaharian utama. Ketika penerima manfaat menjalankan usaha setiap hari, maka nilai dampak akan terus terakumulasi. Berdasarkan hasil ini, maka usaha pemberdayaan masyarakat yang menyasar pada peningkatan kesejahteraan melalui peningkatan pendapatan, perlu dirancang agar mendukung usaha pokok atau merangsang tumbuhnya usaha utama oleh penerima manfaat. Program pemberdayaan harus memperhatikan kesesuaian program dengan kondisi masyarakat lokal. Hasil ini mengkonfirmasi hasil studi (Vik, 2017) bahwa hasil penghitungan SROI dipengaruhi oleh rutinitas aktivitas yang terdampak oleh program. Proses penghitungan SROI mengakumulasikan nilai dampak yang muncul di sepanjang periode penghitungan. Semakin lama periode maka, nilai SROI berpotensi semakin meningkat. Sejalan dengan hal teresbut, semakin sering kegiatan tindak lanjut program dilaksanakan, nilai SROI juga akan semakin besar.

Ketika program pemberdayaan masyarakat diselenggarakan di komunitas yang belum memiliki kegiatan yang stabil, maka program perlu dirancang untuk meningkatkan kapasitas masyarakat menjalankan usaha sampai kondisi yang mapan. Program pada kondisi masyarakat yang seperti ini memerlukan waktu yang relatif lama sampai dampak dapat tercipta oleh 
tindak lanjut penerima manfaat. Di samping itu, dukungan sumber daya untuk menjalankan usaha juga menjadi faktor penentu berjalannya usaha. Perusahaan melalui CSR, penguasaan teknologi, komitmen untuk memobilisasi sumber daya, dan fleksibilitas kelembagaan memiliki peluang besar untuk merealisasikan usaha tersebut.

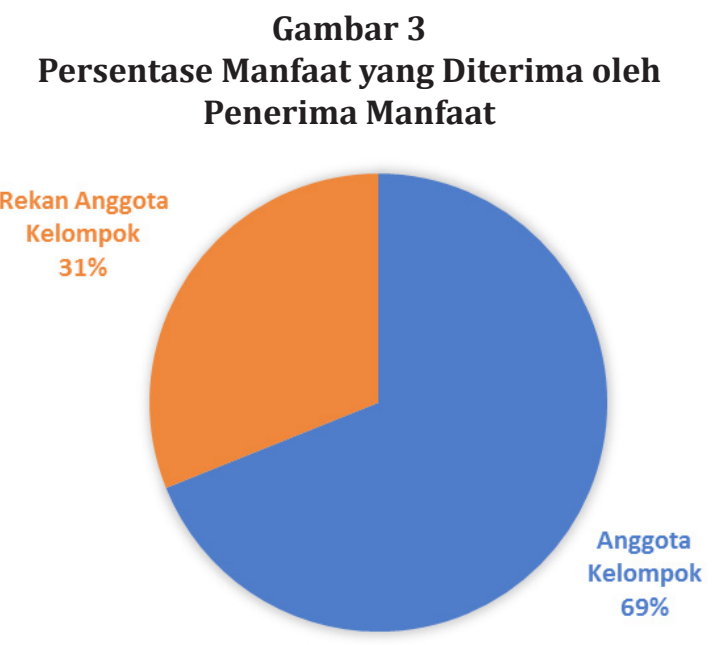

Sumber: Penulis, 2020

Dapat dilihat pada gambar 3 bahwa 69 persen manfaat dinikmati oleh kelompok pencari madu Biene sedangkan 31 persen dinikmati oleh rekan anggota kelompokyang ikut menjalankan budidaya madu. Satu orang mampu menghasilkan 31 persen manfaat dibandingkan satu kelompok yang menghasilkan 69 persen manfaat menunjukkan bahwa kapasitas penerima manfaat dalam menindaklanjuti program berperan penting dalam program intervensi sosial.

Rekan dari anggota kelompok yang menjalankan usaha budidaya lebah madu ini memiliki kapasitas untuk mendirikan usaha sendiri dalam skala yang besar. Inspirasi yang diperoleh dari anggota kelompok pencari madu biene dapat ditindaklanjuti dalam waktu singkat. Sedangkan pada anggota kelompok, keterbatasan sumber daya membuat mereka baru bisa menjalankan budidaya lebah madu memanfaatkan bantuan dari Pertamina Sungai Pakning. Dengan demikian, dapat dilihat bahwa kebermanfaatan program Budidaya Madu Hutan Gambut ditentukan oleh kesesuaian program dengan kondisi kelompok, kapasitas kelompok dalam menindaklanjuti program, dan ketertarikan pemangku kepentingan lain.

\section{Kesimpulan}

Artikel ini menunjukkan bagaimana proses promosi kegiatan produktif ramah lingkungan pada program "Budidaya Madu Hutan Gambut" oleh Pertamina Sungai Pakning dapat berdampak positif pada pendapatan dan kehidupan anggota kelompok pencari madu Biene. Hasil SROI sebesar 1,1 menunjukkan bahwa program menghasilkan manfaat positif yang bernilai lebih besar daripada biaya program. Untuk setiap Rp1 biaya investasi yang dikeluarkan, manfaat yang dihasilkan adalah sebesar Rp1,1. Tambahan biaya produksi yang dikeluarkan untuk mencegah kebakaran lahan ketika mencari madu hutan menghasilkan manfaat dalam bentuk kestabilan pendapatan dan keberlanjutan usaha. Tantangan yang dihadapi adalah menentukan peningkatan skala usaha yang tepat agar dapat meningkatkan kesejahteraan pelaku usaha tanpa melebihi batas daya dukung lingkungan.

Pada program ini, perusahaan melalui CSR nya berperan sentral dalam memfasilitasi implementasi proses produksi yang ramah lingkungan. Penguasaan teknologi, komitmen sosial dan produk (sertifikasi) untuk memobilisasi sumber daya, dan fleksibilitas kelembagaan yang dimiliki perusahaan menjadi modal penting untuk merealisasikan usaha tersebut. Secara keseluruhan, kegiatan pada program ini mendorong peningkatan kualitas modal manusia dari penerima manfaat.

Dari sisi metodologis, studi ini menunjukkan bahwa kebermanfaatan program Budidaya Madu Hutan Gambut dicapai melalui kesesuaian program dengan kondisi kelompok, kapasitas kelompok dalam menindaklanjuti program, dan ketertarikan pemangku kepentingan lain. Pengalaman ini dapat menjadi pelajaran bahwa intervensi sosial yang baik adalah program yang mampu mengakumulasi manfaat secara intensif. Untuk itu, program perlu dirancang agar sesuai dengan karakteristik penerima manfaat serta meningkatkan kapasitas penerima manfaat sehingga bisa mandiri.

Lebih dari itu, diperlukan kehati-hatian dalam menindaklanjuti hasil SROI. Penghitungan nilai SROI diharapkan tidak mengarahkan pengguna studi secara umum untuk hanya memilih kelompok yang sudah berdaya demi mendapatkan nilai SROI yang tinggi. Pengguna diharapkan fokus pada peningkatan kapasitas penerima manfaat agar bisa mandiri serta mengembangkan program yang bisa menjadi usaha pokok penerima manfaat. 
Rezaldi Alief Pramadha, Vandy Yoga Swara, Rudi Hartono, D. Satria Wijaya, Rahmad Hidayat - Analisis Laba Sosial atas Investasi: Menyibak Asap Panen Madu Hutan Gambut untuk Kesejahteraan yang Lebih Cerah

\section{Referensi}

Adeleke, 0., \& Josue, M. (2019). Poverty and green economy in South Africa: What is the nexus? Cogent Economics and Finance, 7(1), pp. 1-14. doi: https://doi.org/10.1080/233 22039.2019.1646847

Bellucci, M., Nitti, C., Franchi, S., Testi, E., \& Bagnoli, L. (2019). Accounting for social return on investment (SROI): The costs and benefits of family-centred care by the Ronald McDonald House Charities. Social Enterprise Journal, 15(1), pp. 46-75. doi: https://doi. org/10.1108/SEJ-05-2018-0044

Canton, E. (2009). Human Capital Externalities and Proximity: Evidence from Repeated Cross-Sectional Data. De Economist, 157(1), pp. 79-105. doi: https://doi.org/10.1007/ s10645-009-9118-5

Cochran, P. L. (2007). The evolution of corporate social responsibility. Business Horizons, 50(6), pp. 449-454. doi: https://doi. org/10.1016/j.bushor.2007.06.004

ElAlfy, A., Palaschuk, N., El-Bassiouny, D., Wilson, J., \& Weber, O. (2020). Scoping the Evolution of Corporate Social Responsibility (CSR) Research in the Sustainable Development Goals (SDGs) Era. Sustainability, 12(14), pp. 1-21. doi: https://doi.org/10.3390/ su12145544

ElAlfy, A., \& Weber, O. (2019). Corporate Sustainability Reporting The Case of the Banking Industry. 211, 32.

Feng, C., Wang, M., Liu, G. C., \& Huang, J. B. (2017). Green development performance and its influencing factors: A global perspective. Journal of Cleaner Production, 144, pp. 323-333. doi: https://doi.org/10.1016/j. jclepro.2017.01.005

Field, B. C., \& Field, M. K. (2017). Urban and environmental economics: An introduction. In Environmental Economics: An Introduction (7th ed.). Routledge

Fordham, A. E., \& Robinson, G. M. (2019). Identifying the social values driving corporate social responsibility. Sustainability Science, 14(5), pp. 1409-1424. doi: https:// doi.org/10.1007/s11625-019-00720-w

Gibbon, J., \& Dey, C. (2011b). Developments in Social Impact Measurement in the Third Sector: Scaling Up or Dumbing Down? Social and Environmental Accountability Journal, 31(1), pp. 63-72. doi: https://doi.org/10.1 080/0969160X.2011.556399
Haberl, H., Wiedenhofer, D., Virág, D., Kalt, G., Plank, B., Brockway, P., Fishman, T., Hausknost, D., Krausmann, F., Leon-Gruchalski, B., Mayer, A., Pichler, M., Schaffartzik, A., Sousa, T., Streeck, J., \& Creutzig, F. (2020). A systematic review of the evidence on decoupling of GDP, resource use and GHG emissions, part II: Synthesizing the insights. Environmental Research Letters, 15(6).pp. 1-42. doi: https:// doi.org/10.1088/1748-9326/ab842a

Nicholls, J. Lawlor, E., Neitzert, E., Goodspeed, T., Cupitt, S. (2012). A guide to social return on investment: The SROI network. Accounting for Value.

Kao, T.-Y., Chen, J. C. H., Wu, J.-T. B., \& Yang, M.-H. (2016). Poverty Reduction through Empowerment for Sustainable Development: A Proactive Strategy of Corporate Social Responsibility: A CSR Strategy for Poverty Reduction through Empowerment. Corporate Social Responsibility and Environmental Management, 23(3), pp. 140-149. doi: https://doi.org/10.1002/csr.1365

Kemp, D. (2010). Community relations in the global mining industry: Exploring the internal dimensions of externally orientated work. Corporate Social Responsibility and Environmental Management, 17(1), pp.1-14. doi: https://doi.org/10.1002/csr.195

Kothari, A., Demaria, F., \& Acosta, A. (2014). Buen Vivir, Degrowth and Ecological Swaraj: Alternatives to sustainable development and the Green Economy. Development (Basingstoke), 57(3-4), pp. 362-375. doi: https://doi.org/10.1057/dev.2015.24

Kumi, E., Yeboah, T., \& Kumi, Y. A. (2020). Private sector participation in advancing the Sustainable Development Goals (SDGs) in Ghana: Experiences from the mining and telecommunications sectors. The Extractive Industries and Society, 7(1), pp. 181-190. doi: https://doi.org/10.1016/j.exis.2019.12.008

Lu, J., Liang, M., Zhang, C., Rong, D., Guan, H., Mazeikaite, K., \& Streimikis, J. (2021). Assessment of corporate social responsibility by addressing sustainable development goals. Corporate Social Responsibility and Environmental Management, 28(2), pp. 686703. doi: https://doi.org/10.1002/csr.2081

Luke, B., Barraket, J., \& Eversole, R. (2013). Measurement as legitimacy versus legitimacy of measures: Performance evaluation of social enterprise. Qualitative Research in 
Accounting and Management, 10(3-4), pp. 234-258. doi: https://doi.org/10.1108/ QRAM-08-2012-0034

Maier, F. (2015). SROI as a Method for Evaluation Research: Understanding Merits and Limitations. 26.

Mannan, M. (2009). BRAC: Anatomy of a "poverty enterprise": BRAC: Anatomy of a "Poverty Enterprise". Nonprofit Management and Leadership, 20(2), pp. 219-233. doi: https:// doi.org/10.1002/nml.250

Marín, L., Rubio, A., \& de Maya, S. R. (2012). Competitiveness as a Strategic Outcome of Corporate Social Responsibility: Competitiveness and CSR. Corporate Social Responsibility and Environmental Management, 19(6), pp. 364-376. doi: https://doi.org/10.1002/csr.1288

Mcmichael, P. (2014). Development and Social Change: A Global Perspective. SAGE Publications.

Muthuri, J. N., Moon, J., \& Idemudia, U. (2012). Corporate Innovation and Sustainable Community Development in Developing Countries. Business \& Society, 51(3), pp. 355-381. doi: https://doi. org/10.1177/0007650312446441

Pesmatzoglou, D., Nikolaou, I. E., Evangelinos, K. I., \& Allan, S. (2014). EXTRACTIVE MULTINATIONALS AND CORPORATE SOCIAL RESPONSIBILITY: A COMMITMENT TOWARDS ACHIEVING THE GOALS OF SUSTAINABLE DEVELOPMENT OR ONLY A MANAGEMENT STRATEGY?: Extractive Multinationals and CSR Strategy. Journal of International Development, 26(2), pp. 187206. doi: https://doi.org/10.1002/jid.2871

Porter M.E. \& Kramer M.R. (2006). Strategy and society: The Link Between Competitive Advantage and Corporate Social Responsibility. Harvard Business Review, 84, pp. 78-92.

Raworth, K. (2017). Doughnuts Economics: Seven Ways to Think Like a 21st-Century Economist. Chelsea Green Publishing.

Renneboog, L., Ter Horst, J., \& Zhang, C. (2008). Socially responsible investments: Institutional aspects, performance, and investor behavior. Journal of Banking \& Finance, 32(9), pp. 1723-1742. doi: https:// doi.org/10.1016/j.jbankfin.2007.12.039

Ruggerio, C. A. (2021). Sustainability and sustainable development: A review of principles and definitions. Science of the Total Environment, 786, pp.1-22. doi: https://doi. org/10.1016/j.scitotenv.2021.147481

Schoot J., \& Fischer, K. (1993). Environmental Strategies for Industry: International Perspectives on Research Needs and Policy Implications. Washington, DC: Island Press.

Sheehy, B. (2015). Defining CSR: Problems and Solutions. Journal of Business Ethics, 131(3), pp. 625-648. doi: https://doi.org/10.1007/ s10551-014-2281-x

Swinton, D. H. (1987). Economic theory and working class poverty towards a reformulation. The American Economic Review, 77(2), pp. 223-228.

Todaro, M. P., \& Smith, S. C. (2012). Economic Development (11th ed.). Addison-Wesley.

Vik, P. (2017). What's So Social About Social Return on Investment? A Critique of Quantitative Social Accounting Approaches Drawing on Experiences of International Microfinance. Social and Environmental Accountability Journal, 37(1), pp. 6-17. doi: https://doi.org/10.1080/096916 0X.2016.1263967

Watson, K. J., Evans, J., Karvonen, A., \& Whitley, T. (2016). Capturing the social value of buildings: The promise of Social Return on Investment (SROI). Building and Environment, 103, pp. 289-301. doi: https:// doi.org/10.1016/j.buildenv.2016.04.007

Whelan, G. (2015). Understanding the social value and well-being benefits created by museums: A case for social return on investment methodology. Arts and Health, 7(3), pp. 216-230. doi: https://doi.org/10 $.1080 / 17533015.2015 .1065574$

Yakovleva, N., Kotilainen, J., \& Toivakka, M. (2017). Reflections on the opportunities for mining companies to contribute to the United Nations Sustainable Development Goals in sub - Saharan Africa. The Extractive Industries and Society, 4(3), pp. 426-433. doi: https://doi.org/10.1016/j.exis.2017.06.010 